\title{
Tranexamic acid is beneficial for reducing perioperative blood loss in transurethral resection of the prostate
}

\author{
QIAN-QIAN MENG, NING PAN, JUN-YU XIONG and NA LIU
}

Department of Anesthesiology, Second Affiliated Hospital, Dalian Medical University, Dalian, Liaoning 116027, P.R. China

Received February 13, 2016; Accepted February 6, 2017

DOI: $10.3892 /$ etm.2018.7025

\begin{abstract}
The aim of this randomized controlled trial was to evaluate the effect of tranexamic acid (TXA) on postoperative blood loss during transurethral resection of the prostate (TURP) for benign prostatic hyperplasia (BPH). A total of 60 patients with $\mathrm{BPH}$ and undergoing TURP were randomized into TXA and control groups. Patients were intravenously administered $1 \mathrm{~g}$ TXA or placebo $(0.9 \%$ sodium chloride solution), respectively, after the induction of anesthesia for TURP. Intraoperative and postoperative bladder irrigation volumes and blood loss volumes were compared between the two groups. Coagulation function (measured by prothrombin, activated partial thromboplastin and thrombin time and fibrinogen levels) was measured before the operation and at $4 \mathrm{~h}$ post-operation. Complications from thromboembolic events, such as lower-limb and pulmonary embolisms, were also noted. The TXA group had significantly decreased blood loss intraoperatively and at $4 \mathrm{~h}$ postoperatively compared with the control group $(\mathrm{P}<0.05)$. The $24 \mathrm{~h}$ postoperative blood loss and coagulation function of the two groups were not significantly different. No thromboembolic events or other complications occurred in either group. In conclusion, a preoperative single dose of TXA was indicated to reduce perioperative blood loss in TURP without a notable increase in thrombosis risk.
\end{abstract}

\section{Introduction}

Benign prostatic hyperplasia (BPH) is among the most common diseases in elderly patients with urinary tract obstructions (1). $\mathrm{BPH}$ is a nonmalignant enlargement of the prostate gland caused by cellular hyperplasia of the glandular and stromal elements; $\mathrm{BPH}$ leads to troublesome lower urinary tract symptoms in some men. Transurethral resection of prostate (TURP) is one of the most common and well-developed technologies used to

Correspondence to: Dr Ning Pan, Department of Anesthesiology, Second Affiliated Hospital, Dalian Medical University, 467 Zhongshan Road, Dalian, Liaoning 116027, P.R. China

E-mail: nn_doctor@163.com

Key words: tranexamic acid, transurethral resection of the prostate, hemorrhage, hemostasis, anesthesia treat BPH. It is recognized as the gold standard for surgical $\mathrm{BPH}$ treatments (2) and has replaced traditional open surgeries. However, because the surrounding prostate tissue contains large venous sinuses, these can easily be breached during the surgery, which can cause complications such as bleeding and TURP syndrome (3); in fact, hemorrhage is the most common complication of this type of surgery (4). Additionally, hemorrhage can cause water poisoning, and severe cases can lead to hemorrhagic shock and affect patient prognoses (5).

Tranexamic acid (TXA) is a type of synthetic fibrinolysis resistance drug that has been demonstrated to be effective for decreasing blood loss in multiple surgical procedures $(6,7)$. TXA has been used across a wide range of clinical setting to control hemorrhaging in cardiac surgery (8), liver transplantation (9), urological surgery (2) and orthopedic surgery (10).

The aim of this prospective randomized controlled study was to evaluate the effect of TXA on perioperative blood loss during TURP. Additionally, the safety of TXA use during TURP surgery was evaluated and discussed.

\section{Materials and methods}

Patient recruitment. This research was approved by the Dalian Medical University Second Affiliated Hospital Ethics Committee (Dalian, China). Informed consent was obtained from all patients. A total of 60 male patients diagnosed with BPH and undergoing TURP were recruited between January 2012 and February 2013 based on the following inclusion criteria: American Society of Anesthesiologists classification I-III; age, 55-85 years; normal preoperative hemoglobin concentration; and an operative time of 1-3 h. The patients were randomized by medical record number; odd numbers were assigned to the TXA group $(n=30)$ and even numbers were assigned to the control group $(n=30)$. The TXA and control groups were intravenously administered with $1 \mathrm{~g}$ TXA (Wuhan Aimin pharmaceutical Co., Ltd., Ezhou, China) in $200 \mathrm{ml}$ saline or a placebo (an equal volume of saline only), respectively, after induction of anesthesia. All surgeries were performed by the same surgeon. The following examinations were performed before surgery: A routine blood examination and urine test, a digital rectum examination, transrectal ultrasound, a test for prostate-specific antigen levels, urodynamics and international prostate symptom score assessment. The exclusion criteria were as follows: Preoperative heart and cerebrovascular diseases, renal insufficiency, kidney stones, 
high risk or a history of thrombosis, long-term anticoagulant therapy, preoperative long-term bed confinement, prostate cancer diagnosis, blood coagulation dysfunction. Patients were also excluded if they had taken 5 -a reductase inhibitors, aspirin or warfarin prior to surgery.

Experimental protocol. All of the operations were performed by the same surgeon with the patients under general anesthesia. To induce anesthesia, patients were intravenously administered with $0.05 \mathrm{mg} / \mathrm{kg}$ midazolam (Jiangsu Enhua Pharmaceutical Co., Ltd., Xuzhou, China), $0.4 \mu \mathrm{g} / \mathrm{kg}$ sufentanil (Yichang Humanwell Pharmaceutical Co., Ltd., Yichang, China), $0.3 \mathrm{mg} / \mathrm{kg}$ etomidate (Jiangsu Enhua Pharmaceutical Co., Ltd.) and $0.2 \mathrm{mg} / \mathrm{kg}$ cisatracurium besylate (Jiangsu Hengrui Medicine Co., Ltd., Lianyungang, China). After administering oxygen for 2-4 min, a laryngeal mask was inserted. During the intraoperative period, propofol and remifentanil were continuously administered to maintain a bispectral index value of $50 \pm 5$. The intraoperative infusion volume and infusion speed were adjusted by central venous pressure. TXA group patients received $1 \mathrm{~g}$ TXA in $200 \mathrm{ml}$ of normal saline after anesthesia induction, while the control group patients received a placebo ( $200 \mathrm{ml}$ normal saline) after anesthesia induction. The medication drip speed was 20-30 drops/min. The experimental drug was administered by an anesthesia nurse, and the surgeon was blinded to the patient groups.

Measurement of experimental outcomes. The intraoperative and postoperative blood loss volumes for each patient were measured by a nurse who was blinded to the patient groups. Bladder irrigation fluid was collected at three time points: Immediately following the operation $\left(\mathrm{T}_{1}\right)$ and $4 \mathrm{~h}$ post-operation $\left(\mathrm{T}_{2}\right)$ and $24 \mathrm{~h}$ post-operation $\left(\mathrm{T}_{3}\right)$. The total volume was measured and 5,000 $\mathrm{U}$ oheparin was added to the flushing fluid containers. After the fluids were fully mixed, $5-\mathrm{ml}$ samples were drawn and subjected to cyanide methemoglobin spectrophotometer colorimetry to evaluate hemoglobin (HB) concentration at a wavelength of $540 \mathrm{~nm}$. Blood loss was then calculated using the following formulae: i) HB concentration in washing liquid $(\mathrm{g} / \mathrm{l})=$ absorbance of fluid $\mathrm{x} 367.7$; ii) Bleeding volume $(\mathrm{ml})=\mathrm{HB}$ concentration in washing liquid $(\mathrm{g} / \mathrm{l}) \times$ Rinse volume (ml)/Preoperative hemoglobin concentration (g/l) (11).

Coagulation functions (including prothrombin, activated partial thromboplastin and thrombin clotting times and fibrinogen level) of the two groups were measured pre-operation and at $4 \mathrm{~h}$ post-operation. Any signs of thromboembolic events, including lower-limb and pulmonary embolisms, were noted.

Statistical analysis. The statistical analyses were performed using SPSS 18.0 (SPSS, Inc., Chicago, IL, USA). All data are presented as the mean \pm standard deviation. The analyses were performed using two-tailed t-tests. $\mathrm{P}<0.05$ was considered to indicate a statistically significant difference.

\section{Results}

Patient characteristics. No significant differences were observed between the two groups with regard to age, height, weight, prostate size, postoperative bladder washing time, surgery duration or length of hospital stay (Table I). In
Table I. Perioperative patient data.

\begin{tabular}{lcc}
\hline Parameter & Tranexamic acid & Control \\
\hline Age (years) & $71.4 \pm 5.4$ & $70.7 \pm 8.5$ \\
Weight $(\mathrm{kg})$ & $75.0 \pm 8.9$ & $71.4 \pm 3.6$ \\
Preoperative hemoglobin $(\mathrm{g} / \mathrm{l})$ & $137.9 \pm 10.7$ & $143.1 \pm 8.7$ \\
Postoperative hemoglobin $(\mathrm{g} / \mathrm{l})$ & $124.0 \pm 10.4$ & $121.7 \pm 14.7$ \\
Size of the prostate $(\mathrm{ml})$ & $73.3 \pm 8.3$ & $66.6 \pm 3.9$ \\
Postoperative bladder irrigation & $25.0 \pm 2.2$ & $24.3 \pm 2.3$ \\
time (h) & & \\
Duration of operation (min) & $101.7 \pm 8.9$ & $89.7 \pm 5.2$ \\
Length of hospitalization (days) & $15.9 \pm 5.2$ & $13.9 \pm 3.9$ \\
\hline
\end{tabular}

the TXA group, the preoperative and postoperative hemoglobin concentrations were $137.9 \pm 10.7$ and $124.0 \pm 10.4 \mathrm{~g} / \mathrm{l}$, respectively. In the control group, the preoperative and postoperative hemoglobin concentrations were $143.1 \pm 8.7$ and $121.7 \pm 14.7 \mathrm{~g} / \mathrm{l}$, respectively. There were no significant differences in hemoglobin concentration between the two groups at either time point. In summary, no significant difference in the basic conditions were identified between the two groups of patients.

Coagulation function. No significant difference was observed in the coagulation function of the two groups. There was no evidence of lower-limb deep vein thrombosis or pulmonary embolism in either group (Table II).

Bladder irrigation volume. No significant difference was observed in the bladder irrigation volume of the two groups at any of the three time points $\left(\mathrm{T}_{1}, \mathrm{~T}_{2}\right.$ and $\left.\mathrm{T}_{3}\right)$ (Table III).

Blood loss. The blood loss at $\mathrm{T}_{1}$ and $\mathrm{T}_{2}$ in the TXA group was $102.0 \pm 11.4$ and $61.9 \pm 6.1 \mathrm{ml}$, respectively. In the control group, the blood loss at these times was $303.6 \pm 24.8$ and $84.8 \pm 15.2 \mathrm{ml}$, respectively. According to these findings, hemoglobin losses at $\mathrm{T}_{1}$ and $\mathrm{T}_{2}$ were significantly lower in the TXA group compared with the control group $(\mathrm{P}=0.002$ and $\mathrm{P}=0.035$, respectively; Table IV). Blood loss at $\mathrm{T}_{3}$ was not significantly different between the two groups.

\section{Discussion}

The results of the current study indicated that TXA could reduce intraoperative and $4 \mathrm{~h}$ postoperative blood loss resulting from TURP surgery, but it had no significant impact on $24 \mathrm{~h}$ postoperative blood loss. Kumsar et al (12) reported that $10 \mathrm{mg} / \mathrm{kg}$ TXA administered $30 \mathrm{~min}$ before surgery significantly reduced hemoglobin loss per $1 \mathrm{~g}$ prostate tissue. Rannikko et al (13) randomly selected 136 patients who were undergoing TURP surgery and administered $2 \mathrm{~g}$ TXA or placebo preoperatively. It was observed that $50 \%$ of the TXA group showed reduced intraoperative bleeding (13). In the current study, it was observed that in the TXA group, intraoperative blood loss was significantly lower compared with the control group. This suggests that TXA could help to 
Table II. Coagulation rates before and after transurethral resection of the prostate $(n=30)$.

\begin{tabular}{|c|c|c|c|c|c|c|c|c|}
\hline \multirow[b]{2}{*}{ Group } & \multicolumn{4}{|c|}{ Pre-operation } & \multicolumn{4}{|c|}{$4 \mathrm{~h}$ post-operation } \\
\hline & PT (sec) & APTT (sec) & $\mathrm{FB}(\mathrm{g} / \mathrm{l})$ & TT (s) & PT (sec) & APTT (sec) & $\mathrm{FB}(\mathrm{g} / \mathrm{l})$ & $\mathrm{TT}(\mathrm{sec})$ \\
\hline Tranexamic acid & $12.6 \pm 0.7$ & $35.8 \pm 3.1$ & $4.1 \pm 1.3$ & $16.3 \pm 1.1$ & $12.8 \pm 0.7$ & $36.0 \pm 3.1$ & $4.0 \pm 1.3$ & $16.3 \pm 1.4$ \\
\hline Control & $12.4 \pm 0.7$ & $35.2 \pm 3.0$ & $3.9 \pm 1.3$ & $17.1 \pm 1.2$ & $13.0 \pm 0.8$ & $35.6 \pm 3.2$ & $3.8 \pm 1.0$ & $17.5 \pm 1.5$ \\
\hline
\end{tabular}

PT, prothrombin time; APTT, activated partial thromboplastin time; FB, fibrinogen level; TT, thrombin clotting time.

Table III. Bladder irrigation volume (1) at three time points after transurethral resection of the prostate.

\begin{tabular}{lccc}
\hline Group & $\mathrm{T}_{1}$ & $\mathrm{~T}_{2}$ & $\mathrm{~T}_{3}$ \\
\hline Tranexamic acid & $27.5 \pm 1.8$ & $0.7 \pm 0.1$ & $18.3 \pm 0.7$ \\
Control & $25.7 \pm 0.9$ & $0.8 \pm 0.1$ & $17.6 \pm 0.8$ \\
\hline
\end{tabular}

$\mathrm{T}_{1}$, the intraoperative operation; $\mathrm{T}_{2}, 4 \mathrm{~h}$ post-operation; $\mathrm{T}_{3}, 24 \mathrm{~h}$ postoperation.

Table IV. Blood loss (ml) at three time points after transurethral resection of the prostate.

\begin{tabular}{lccc}
\hline Group & $\mathrm{T}_{1}$ & $\mathrm{~T}_{2}$ & $\mathrm{~T}_{3}$ \\
\hline Tranexamic acid & $102.0 \pm 11.4^{\mathrm{a}}$ & $61.9 \pm 6.1^{\mathrm{a}}$ & $63.9 \pm 5.2$ \\
Control & $303.6 \pm 24.8$ & $84.8 \pm 15.2$ & $77.4 \pm 5.0$ \\
\hline
\end{tabular}

$\mathrm{T}_{1}$, the intraoperative operation; $\mathrm{T}_{2}, 4 \mathrm{~h}$ post-operation; $\mathrm{T}_{3}, 24 \mathrm{~h}$ postoperation. ${ }^{\mathrm{a}} \mathrm{P}<0.05$ vs. control.

reduce patient trauma and decrease the intraoperative blood transfusion risk.

The prostate has a rich blood supply, and the surrounding tissue contains large venous sinuses (4). When an electric scalpel is used to remove prostate tissue, the electric knife squeezes the venous sinuses, which releases a large number of fibrinolytic enzymes into the blood and activates the fibrinolysis system (14). The affected fibrin then dissolves into soluble fibrin degradation products, which causes bleeding (15).

TXA is a synthetic anti-fibrinolytic with a chemical structure similar to that of lysine $(16,17)$. It can restrain the fibrinolytic enzyme adsorption of fibrin and promote blood clot formation; thus, it has hemostatic effects during TURP surgery $(18,19)$. The half-life of TXA is approximately $3 \mathrm{~h}$ if the intravenous injection dosage is $15 \mathrm{mg} / \mathrm{kg}$ (4). According to the manufacturer's specification, at $1 \mathrm{~h}$, the blood concentration is $20 \mu \mathrm{g} / \mathrm{ml}$, and at $4 \mathrm{~h}$, the blood concentration is $5 \mu \mathrm{g} / \mathrm{ml}$. In the current study, TXA was administered immediately after anesthesia, and the surgery was conducted over the following 1-3 h. It was observed that TXA had the greatest hemostatic effects during surgery and at $4 \mathrm{~h}$ post-operation. There is no single recommended mode of delivery or dosage for TXA when it is applied in a variety of surgical procedures $(8,20,21)$. For prostate surgery, the manufacturer suggests reducing the drug dosage in elderly patients. In this study, $1 \mathrm{~g}$ of the drug was used, and the drip speed was controlled, which not only achieved good hemostatic effects with no complications, but also demonstrated that this method was reasonable and effective.

Given TXA's effects on intraoperative blood loss, its influence on postoperative blood loss was also investigated in the current study. Previous studies have reported that postoperative bleeding during TURP surgery is associated with excessive fibrinolytic system activation, which TXA reduces to achieve a hemostatic effect $(7,22)$. When the statistical results were combined, the postoperative bladder irrigation times for the two patient groups, which were operated on by the same surgeon, were not significantly different. After TXA administration, however, the blood loss at $4 \mathrm{~h}$ post-operation was significantly reduced, indicating that TXA improved styptic effects within $4 \mathrm{~h}$ after surgery. However, TXA had no significant effect on blood loss $24 \mathrm{~h}$ after surgery. The authors of the current study speculated that, without pain stimulation for prostate tissue resection, catheter indwelling would not have lead to differences in blood loss being identified between the two groups within the $24 \mathrm{~h}$ of the surgery.

Rannikko et al (13) used TXA on the day of surgery and at day 1 post-TURP surgery and found that the bladder irrigation volume of the TXA group was significantly reduced compared with the control group. In the current study, the intraoperative and $24 \mathrm{~h}$ postoperative bladder irrigation volume of the TXA group (27.5 \pm 1.76 and $18.26 \pm 0.701$, respectively) was slightly higher than that of the control group $(25.7 \pm 0.91$ and $17.6 \pm 0.771$, respectively), but the difference was not statistically significant. Therefore, it cannot be concluded with certainty that TXA had any effect on the postoperative bladder irrigation fluid volume.

Given that the availability of aprotinin, a natural anti-fibrinolytic agent, is restricted in China, more attention regarding the side effects of such drugs is needed. Lowe et al (23) demonstrated that an age $>40$ years, surgical time $>30 \mathrm{~min}$, pelvic surgery history and a history of deep vein thrombosis combined with heart failure and cancer increased the perioperative thrombosis risk. Thromboelastography (TEG) is a technology used to monitor the fibrinolytic system (24-26). It can dynamically monitor the level, speed and degree of activity of the fibrinolytic system and of blood clot-forming tendencies between the preoperative and postoperative periods; however, it is not often used in clinical applications. Faraoni et al (27) used TEG to measure fibrinolysis during cardiac surgery in an 
experimental group (two doses of TXA) and a control group (normal saline), but the results were not statistically significant. Chakravarthy et al (28) used TEG to compare the influence of TXA and hydroxyethyl starch on extracorporeal circulation blood loss during heart surgeries; however, these results were not statistically significant either.

Due to limited funding, TEG could not be used in this study. Instead, prothrombin, activated partial thromboplastin and thrombin time and fibrinogen levels were measured directly in the two groups preoperatively and at $4 \mathrm{~h}$ postoperatively. The development of lower-extremity deep vein thromboses or pulmonary embolisms after seven days was also monitored. Compared with younger patients, elderly patients are usually less physically active on a daily basis, and their blood viscosities are higher; therefore, the lithotomy position used during surgery can be a risk factor for thrombosis (23). However, in the current study, the preoperative and $4 \mathrm{~h}$ postoperative coagulation functions were not significantly different. Furthermore, none of the 60 patients had deep vein thromboses or pulmonary embolisms within seven days post-operation, suggesting that TXA treatment does not result in thrombosis.

Previous results have demonstrated that TXA can cause complications, such as postoperative central nervous system convulsions, particularly in relation to the dosage (29). Currently, these findings have only been reported in cardiac surgery patients, and such complications are likely to be the result of TXA blocking GABA receptors in nerve cells (30-34). One study has also reported that the risk of epilepsy is increasing in children who have undergone heart surgery involving TXA treatment (35). Although TURP surgeries have not yet been reported to have such complications, further studies on the postoperative neurological complications of TXA are required.

In conclusion, the current study indicates that the preoperative use of $1 \mathrm{~g}$ TXA administered immediately after anesthesia can reduce intraoperative and $4 \mathrm{~h}$ postoperative blood loss for TURP surgery, with no adverse side effects.

\section{Acknowledgements}

Not applicable.

\section{Funding}

No funding was received.

\section{Availability of data and materials}

The datasets used and/or analyzed during the current study are available from the corresponding author on reasonable request.

\section{Authors' contributions}

JYX contributed to the conception and design of the study. QQM performed the data collection. QQM and NP recruited the patients. QQM, NP and NL performed the spectrophotography and data analysis, and wrote the manuscript. QQM and JYX interpreted the data. JYX and NP revised the article.

\section{Ethics approval and consent to participate}

The current study was performed in the laboratory of the Second Affiliation Hospital of Dalian Medical University and supported by the National Natural Science Foundation of China (grant no. 2012-044 given to JYX). Informed consent was obtained from all patients.

\section{Patient consent for publication}

Not applicable.

\section{Competing interests}

The authors declare that they have no competing interests.

\section{References}

1. Hahn RG: Fluid absorption in endoscopic surgery. $\mathrm{Br}$ JAnaesth 96: 8-20, 2006.

2. Crescenti A, Borghi G, Bignami E, Bertarelli G, Landoni G, Casiraghi GM, Briganti A, Montorsi F, Rigatti P and Zangrillo A: Intraoperative use of tranexamic acid to reduce transfusion rate in patients undergoing radical retropubic prostatectomy: Double blind, randomized, placebo controlled trial. BMJ 343: d5701, 2011.

3. de Médicis É: From the Journal archives: Complications of transurethral prostatic surgery: Back to the future? Can J Anesth 61: 273-277, 2014.

4. Soliman SA, Wadie BS, Ibrahim el-HE and Shehab El-Dein AB: Rotoresection versus transurethral resection of the prostate: Short-term evaluation of a prospective randomized study. J Urol 177: 1036-1039, 2007.

5. Demirel I, Ozer AB, Bayar MK and Erhan OL: TURP syndrome and severe hyponatremia under general anaesthesia. BMJ Case Rep 2012: bcr-2012-006899, 2012.

6. Wang Q, Liu J, Fan R, Chen Y, Yu H, Bi Y, Hua Z, Piao M, Guo M, Ren W and Xiang L: Tranexamic acid reduces postoperative blood loss of degenerative lumbar instability with stenosis in posterior approach lumbar surgery: A randomized controlled trial. Eur Spine J 22: 2035-2038, 2013.

7. Gautam PL, Katyal S, Yamin M and Singh A: Effect of tranexamic acid on blood loss and transfusion requirement in total knee replacement in the Indian population: A case series. Indian J Anaesth 55: 590-593, 2011.

8. Ruel MA, Wang F, Bourke ME, Dupuis JY, Robblee JA, Keon WJ and Rubens FD: Is tranexamic acid safe in patients undergoing coronary endarterectomy? Ann Thorac Surg 71: 1508-1511, 2001.

9. Ramsay MAE: The use of antifibrinolytic agents results in a reduction in transfused blood products during liver transplantation. Liver Transpl Surg 3: 665-668, 1997.

10. Kagoma YK, Crowther MA, Douketis J, Bhandari M, Eikelboom $\mathrm{J}$ and Lim W: Use of antifibrinolytic therapy to reduce transfusion in patients undergoing orthopedic surgery: A systematic review of randomized trials. Thromb Res 123: 687-696, 2009.

11. Qiu SP, Wu RP, Gao X, Cai YB and Liang WB: Clinical study on tranexamic acid in hemostatic treatment after prostatectomy: A comparative multi-center randomized trial. Chin J Urol 26: 305-307, 2005 (In Chinese)

12. Kumsar S, Dirim A, Toksöz S, Sağlam HS and Adsan O: Tranexamic acid decreases blood loss during transurethral resection of the prostate. Cent European J Urol 64: 156-158, 2011.

13. Rannikko A, Pétas A and Taari K: Tranexamic acid in control of primary hemorrhage during transurethral prostatectomy. Urology 64: 955-958, 2004.

14. Nielsen JD, Gram J, Holm-Nielsen A, Fabrin K and Jespersen J: Post-operative blood loss after transurethral prostatectomy is dependent on in situ fibrnolysis. Br J Urol 80: 889-893, 1997.

15. Porte RJ and Leebeek FW: Pharmacological strategies to decrease transfusion requirements in patients undergoing surgery. Drugs 62: 2193-2211, 2002. 
16. Dadure C, Sauter M, Bringuier S, Bigorre M, Raux O, Rochette A, Canaud N and Capdevila X: Intraoperafive tranexamie acid reduces blood transfusion in children undergoing craniosynostosis surgery: A randomized double-blind study. Anesthesiology 114: 856-861, 2011.

17. Abrishami A, Chung $\mathrm{F}$ and Wong J: Topical application of antifibrinolytic drugs for on-pump cardiac surgery: A systematic review and meta-analysis. Can J Anesth 56: 202-212, 2009.

18. Aravinthan $\mathrm{T}$ : Massive haematuria with clot retention: Management options. Sri Lanka J Surg 30: 18-19, 2012.

19. May F, Günther M, Barba M, Fastenmeier K and Hartung R: Coagulating intermittent cutting (CIC) dramatically reduces blood loss intransurethral resection of the prostate: Report from a multicenter trial and identificition of resk groups. Eur Urol 2 $104,2003$.

20. Kumar S, Randhawa MS, Ganesamoni R and Singh SK: Tranexamic acid reduces blood loss during percutaneous nephrolithotomy: A prospective randomized controlled study. J Urol 189: 1757-1761, 2013.

21. Sa-Ngasoongsong $\mathrm{P}$, Channoom $\mathrm{T}$, Kawinwonggowit V, Woratanarat P, Chanplakorn P, Wibulpolprasert B, Wongsak S, Udomsubpayakul U, Wechmongkolgorn S and Lekpittaya N: Postoperative blood loss reduction in computer-assisted surgery total knee replacement by low dose intra-articular tranexamic acid injection together with 2-hour clamp drain: A prospective triple-blinded randomized controlled trial. Orthopedic Rev (Pavia) 3: e12, 2011

22. Breuer T, Martin K, Wilhelm M, Wiesner G, Schreiber C, Hess J, Lange $\mathrm{R}$ and Tassani P: The blood sparing effect and the safety of aprotinin compared with tranexamic acid in paediatric cardiac surgery. Eur J Cardiothorac Surg 35: 167-171, 2009.

23. Lowe GDO, Greer IA, Cooke TG, Dewar EP, Evans MJ, Forbes CD, Mollan RAB, Scurr JH and de Swiss M: Risk of prophylaxis for venous thromboembolism in hospital patients. Thromboembolic Risk Factors (THRIFT) Consensus Group BMJ 305: 567-574, 1992.

24. Mohapatra S, Samantaray JC, Arulselvi S and Ghosh A: Disseminated intravascular coagulation following malaria due to Plasmodium vivax: A thromboelastography based study. Malar J 12: 336, 2013.

25. Bolliger D and Tanaka KA: Roles of Thrombelastography and thromboelastometry for patient blood management in cardiac surgery. Transfus Med Rev 27: 213-220, 2013.

26. Toukh M, Siemens DR, Black A, Robb S, Leveridge M, Graham $\mathrm{CH}$ and Othman M: Thromboelastography identifies hypercoagulablilty and predicts thromboembolic complications in patients with prostate cancer. Thromb Res 133: 88-95, 2014.
27. Faraoni D, Cacheux C, Van AC, Ickx BE, Barvais L and Levy JH: Effect of two doses of tranexamic acid on fibrinolysis evaluated by thromboelastography during cardiac surgery: A pilot, prospective, randomised, controlled study. Eur J Anaesthesiol 31: 491-498, 2014.

28. Chakravarthy M, Muniraj G, Patil S, Suryaprakash S, Mitra S and Shivalingappa B: A randomized prospective analysis of alteration of hemostatic function in patients receiving tranexamic acid and hydroxyethyl starch (130/0.4) undergoing off pump coronary artery bypass surgery. Ann Card Anaesth 15: 105-110, 2012.

29. Murkin JM, Falter F, Granton J, Young B, Burt C and Chu M: High-dose tranexamic acid is associated with nonischemic clinical seizures in cardiac surgical patients. Anesth Analg 110: 350-353, 2010.

30. Koster A and Schirmer U: Re-evaluation of the role of antifibrinolytic therapy with lysine analogs during cardiac surgery in the post aprotininera. Curr Opin Anaesthesiol 24: 92-97, 2011.

31. Bell D, Marasco S, Almeida A and Rowland M: Tranexamic acid in cardiac surgery and postoperative seizures: A case report series. Heart Surg Forum 13: E257-E259, 2010.

32. Sharma V, Katznelson R, Jerath A, Garrido-Olivares L, Carroll J, Rao V, Wasowicz M and Djaiani G: The association between tranexamic acid and convulsive seizures after cardiac surgery: A multivariate analysis in 11529 patients. Anaesthesia 69: 124-30, 2014.

33. Williams-Johnson JA, McDonald AH, Strachan GG and Williams EW: Effects of tranexamic acid on death, vascular occlusive events, and blood transfusion in trauma patients with significant haemorrhage (CRASH-2) a randomised, placebo-controlled trial. West Indian Med J 59: 612-624, 2010.

34. Martin K, Knorr J, Breuer T, Gertler R, Macguill M, Lange R, Tassani P and Wiesner G: Seizures after open heart surgery: Comparison of $\varepsilon$-aminocaproic acid and tranexamic acid. J Cardiothorac Vasc Anesth 25: 20-25, 2011.

35. Martin K, Breuer T, Gertler R, Hapfelmeier A, Schreiber C, Lange R, Hess $\mathrm{J}$ and Wiesner G: Tranexamic acid versus $\varepsilon$-aminocaproic acid: Efficacy and safety in paediatric cardiac surgery. Eur J Cardiothorac Surg 39: 892-897, 2011. 